\title{
EXPERIMENTAL INVESTIGATION OF THE TENSILE AND IMPACT PROPERTIES OF TWILL AND TWILL DERIVATIVE WOVEN FABRIC REINFORCED COMPOSITES
}

\author{
Hakan ÖZDEMİR ${ }^{1}$, Bülent Murat IÇTEN ${ }^{2}$, Akar DOĞAN ${ }^{3}$ \\ ${ }^{I}$ Dokuz Eylül University, Department of Textile Engineering, İzmir, Turkey; \\ ${ }^{2}$ Dokuz Eylül University, Department of Mechanical Engineering, Izmir, Turkey \\ ${ }^{3}$ Munzur University, Department of Mechanical Engineering, Tunceli, Turkey
}

Received: 22.12 .2017

Accepted: 19.09 .2018

\begin{abstract}
In recent years the use of woven composites in structural applications has increased rapidly due to the advantages it offers such as easy handling, dimensional stability, deep drawing shape-ability, enhanced toughness and increased impact resistance. Mechanical properties in textile composites are closely connected with the textile reinforcement's internal structure. This paper reports and discusses a study of the tensile and impact properties of the twill and twill derivative woven fabric reinforced composites. Tensile strength, modulus of elasticity and elongation at break values of the composites were found by tensile tests. In addition impact tests are performed on specimens of woven fabric reinforced composite laminates in order to measure impact strength and characterize damage mechanisms at diverse impact energies. The experimental results reveal that the average float length and weave interlacing coefficient, which are determined by weave pattern, significantly affect the tensile and impact properties of the composites. It is observed that $3 / 1$ twill woven fabric reinforced composite showed the best performance in tensile tests along warp and weft directions. It is also observed that $3 / 1$ twill woven fabric reinforced composite has the lowest impact strengths at the highest deflections; whereas, $3 / 3$ twill woven fabric reinforced composite has the highest impact strengths at the lowest deflections.
\end{abstract}

Keywords: Composites, twill weave, tensile strength, elongation at break, elasticity modulus, impact strength, impact deformation, contact time, absorbed energy, mechanical performance of composites

Corresponding Author: Hakan ÖZDEMİR e-mail: h.ozdemir@deu.edu.tr / DOI: 10.32710/ tekstilvekonfeksiyon.482873

\section{INTRODUCTION}

Due to their high specific strength and stiffness, composite materials are valuable structural materials in engineering applications. Some fields benefiting from the qualities of composites include aerospace, automotive, wind energy, and civil infrastructure. The mechanical properties of composites can be tailored through using various forms of reinforcements. Textiles and woven fabrics, in particular, are increasingly used as the reinforcement phase in laminated composite materials due to their balanced mechanical properties in every in-plane direction of the laminate. Twodimensional (2D) woven fabrics consist of two sets of interlaced yarns known as warp and weft. The fundamental 2D weaves can be classified into plain, twill and satin according to the repeating patterns of the interlaced regions in the warp and weft directions. In twill weaves the yarn floats, which are the sections formed by passing over more than one intersecting yarns, run in the diagonal direction.
The predominant characteristics of the twill structures are flexibility, thick and dense structure, characteristic twill lines. Apart from the twill weaves, there are derivatives of twill weaves. The idea behind developing these weaves is to obtain physical and aesthetic characteristics in the fabric somewhat different than those obtained with the twill weaves. In derivative weaves properties, intermediary between these main groups are obtained. This is achieved by rearranging the twill weave structures by the application of certain methods to give the desired result (1).

A number of studies were carried out to search the tensile and impact properties of woven fabric reinforced composites:

Adumitroaie and Barbero (2) presented a model to predict the mechanical hygro-thermo elastic properties and strength values of composite materials reinforced with plain woven fabric. Chen and Ding (3) used the chain-of-bundles model 
and a Monte Carlo method to simulate the breaking progress of plain weave woven fabrics under uni-axial tensile load and to predict the tensile strength of the fabrics. They observed that under uni-axial tensile loading, the critical length of fabric changed due to the change of crossover point frictional forces resulting from crimp interchange. Dabiryan, Jeddi and Rastgo (4) used the energy method and Castigliano's theorem to investigate the load-extension behavior of plain woven fabrics with respect to friction. They observed that the effect of friction between components of fabric, yarns and fibers, on load-extension behavior, was more important than the reciprocal effect of yarns.

Bilişik, Karaduman and Bilişik (5) reviewed two-dimensional and three-dimensional fabric architectures, processes and some of their properties. Adanur and Önal (6) evaluated the mechanical properties of plain woven fabric reinforced glass/graphite-epoxy hybrid composite materials. They found that thickness of the composite and hybrid combination had effect on stress-strain and impact properties. Pothan et al. (7) investigated the effect of weave architecture on the ultimate mechanical properties of plain, twill and matt woven sisal fiber reinforced polyester composites prepared by the resin transfer moulding technique. They observed that while the tensile strength showed an improvement of $52 \%$, the tensile modulus gave an improvement of $100 \%$ in the case of composites with matt-weave architecture. Shonaike, Lang and Odusanya (8) studied the tensile properties of the glass mat plain woven fabric reinforced santoprene composites. They found that the tensile properties of the composites depend on the quantity of voids; i.e., the higher the void content, the lower the tensile properties.

Chen et al. (9) produced and tested six different two-layer structures, each using a combination of two weaves from a plain fabric and two four-pick twills $(2 / 2$ and $1 / 3)$. They observed that the impact of the weave combination on the tensile strength was not very obvious.

Perumalraj, Dasaradhan and Nalankilli (10) studied the physical and mechanical properties of copper core yarn, stainless core yarn, glass core yarn, and copper ply yarn of plain, twill and sateen woven fabric composite materials. They observed that there was strong and significant difference between the tensile strength of warp direction and weft direction of core yarn woven fabric composite materials.

Karahan (11) investigated the mechanical behaviour and damage of a 2/2 twill woven carbon/epoxy composite resulting from uniaxial tension in the warp and bias directions. Microscopic examination showed that damage or cracks initiated where the yarn was crimped and at interactions between the warp and filling yarns. Abot, Gabbai and Harsley (12) investigated composite specimens with five different architectures, uniweave, cross-ply uniweave, plain, 2/2 twill, and five-harness satin weaves. This strength of the composites specimens with 2/2 twill weave reinforcement is slightly higher than those with fiveharness satin weave reinforcement and in turn higher than those with plain weave reinforcement. Arju et al. (13) investigated the effects of fabric structures on the performance of jute composites. Composites having twill structure fabrics had the highest value of tensile strength (48 MPa), which was $134 \%$ higher than that of composites having plain structure fabrics.

Bilişik (14) conducted pull-out test on para-aramid Twaron (R) woven fabrics. He observed that the amount of stick-slip force was related to the number of interlacement points in the fabric whereas the amount of accumulative retraction force was related to fabric structural response.

Bilişik and Yolaçan (15) investigated the warp and weft directional tensile properties of the two-dimensional multistitched multilayer E-glass/polyester woven composites. They found that the failure of warp and weft directional multi-stitched woven E-glass/polyester composite structures was matrix breakages, and partial and complete yarn breakages in their surfaces. In other study (16), they searched the low-velocity impact energy absorption mechanism of the developed two-dimensional multi-stitched multilayer E-glass/polyester-woven composites. They found that impact load caused a small indentation in the centre of front face and resulted in fiber splitting and fiber breakages in the centre of the back face of the structure. On the surrounding area of the front and back face damaged zones of the structures, fibre-matrix debonding and matrix breakages were observed.

Özdemir and İçten (17) investigated the mechanical performance of the plain and plain derivative woven fabric reinforced composites. The results reveal that the weaving pattern affects the tensile and impact properties of the composites. It is observed that $2 / 2$ matt woven fabric reinforced composite showed the best performance in tensile tests along warp direction; whereas, $2 / 2$ warp rib woven fabric reinforced composite showed the best performance during tensile tests in weft direction. 3/1 matt woven fabric reinforced composite absorbs the most energy for perforation.

Aly et al. (18) produced 27 types of woven fabrics using polyester fibres as warp threads with different structure parameters such as weft yarn material, picks densities, and weaving structures to be used as skin layers and nonwoven fabric was used as core layer. They found that the impact properties were strongly affected by woven fabric structure parameters and the resin properties.

Yan and Cheng (19) investigated the ballistic impact mechanism of multi-ply aramid/epoxy composites with different laying up structures. The results of the investigation indicated that for three-layered composites, [0/45/0] and [0/30/60] angle-laid constructions absorbed $3 \%$ and $10 \%$ more energy than the composite with align-laid reinforcement. However, for the four-layered composites, angle-laid composites demonstrated lower ballistic resistance than the align-laid composites.

Padaki et al. (20) studied the influence of interlacements in the multilayer woven interlocked 3D structures on the impact properties of the composite material reinforced with them. They observed that increased interlacement in the structure improved the impact resistance of the multilayer textile composites. Hosur et al. (21) investigated the response of seven layer plain and satin weave carbon fabric reinforced composites under low-velocity impact loading. It is observed 
that satin weave fabric composites exhibited better impact resistance as compared to plain woven fabric composites. Naik and Reddy (22) carried out experimental studies on the damage evolution in a typical plain woven fabric composite plate under transverse quasi-static loading. They observed that the damage propagation along the warp/fill was more than the damage along other directions. Naik et al. (23) carried out experimental studies on the impact behaviour of plain woven E-glass-epoxy laminates with different combinations of impactor mass and incident impact velocity with the same incident impact energy. They observed that for the materials tested, damage tolerance was higher for low mass and high velocity combination as compared to high mass and low velocity combination. Another study (24) was carried out on E-glass/epoxy and T300/5208 carbon/epoxy plain woven fabric composites. It is observed that the use of incident impact energy alone as a parameter to characterize the impact behaviour was inadequate. Instead, the effect of both incident impact velocity and impactor mass should be considered separately. In other work (25), the behaviour of woven-fabric laminated composite plates was studied under transverse central lowvelocity point impact by using a modified Hertz law and a 3D transient finite-element analysis code. For comparison, the impact behaviour of balanced, symmetric, cross ply laminates made of unidirectional layers and unidirectional composites has been included. It is observed that the inplane failure function is lower for woven-fabric laminates than for cross ply laminates, indicating that woven-fabric laminates are more resistant to impact damage.

Atas and Sayman (26) presented an overall view on impact response of woven fabric composite plates made of E-glass as reinforcing material and epoxy resin as matrix material. They performed a number of tests under various incident impact energies ranging from approximately $4-45 \mathrm{~J}$. It was shown that the damage process of individual specimens can be reconstructed from comparing the corresponding loaddeflection curves, energy profile diagram and images of damaged specimens.

Mariatti et al. (27) studied the properties of unsaturated polyester reinforced with banana and pandanusplain woven fabric. They observed that the flexural and impact properties of both natural fibre composites were higher than pure polyester. Banana woven composites exhibited higher flexural and impact properties due to the difference structure in cross section, and higher cellulose content compared to that of pandanus woven composites.

Sinnppoo, Arnold and Padhye (28) found that high velocity ballistic impacts of multi-layered plain woven panels designed can be improved if wool is incorporated into the weave structure. Marsyahyo et al. (29) investigated the ballistic performance of ramie plain woven reinforced composites. They found that ramie fibres had sufficient breaking strength and toughness for level II bullet testing. Pothan et al. (30) determined the static and dynamic mechanical properties of plain banana and glass woven fabric-reinforced polyester composites. They found that impact strength of the composites increased with the number of layers and the fibre volume fraction.
The studies in literature focused on composites reinforced with fabrics, which were woven with basic weaves such as plain, twill and satin. However, the tensile and impact properties of composites reinforced with fabrics, which are woven with derivative of twill and twill weaves, have not been compared. The first aim of this study is to investigate the effect of weave on the elasticity modulus, tensile strength, elongation at break and impact behaviour of the composites reinforced with twill and derivative of twill woven fabrics. The second aim of this study is to compare the properties of composites reinforced with twill woven composites within each other and with those of composites reinforced with derivative of twill woven fabric. In this regard, an experimental study was carried out and then the effects of the parameters were detected firstly by graphs formed by obtained data and secondly by analysis of variance.

\section{EXPERIMENTAL STUDY}

\subsection{Production of carcass woven fabrics}

In this research five types of woven fabric specimens $(42 \times 168 \mathrm{~cm})$, which were used as carcass in composite constructions, were produced in Weaving Workshop of inhouse by $\mathrm{CCl}$ automatic sample rapier loom (Evergreen 8900, Taiwan). Nm 20/5 (2250 denier) staple fibre of folded polyester (polyethylene terephthalate) yarn, which has high tenacity, required property for composites, was used. Longitudinal view of polyester fibre, taken by OLYMPUS BX43 model optical microscope with magnification of 200x, is shown in Figure 1. Fibre cross section is circular. Fibre diameter was measured as $11,5 \mu \mathrm{m}$, by OLYMPUS LC software. In woven fabrics, warp yarns carry loads more than weft yarns; therefore, in this research, warp rib woven fabrics were selected as carcass woven fabrics instead of weft rib woven fabrics. Derivative of plain weave patterns are shown in Figure 2. Carcass fabric specimens were coded according to their weave pattern as in Table 1.

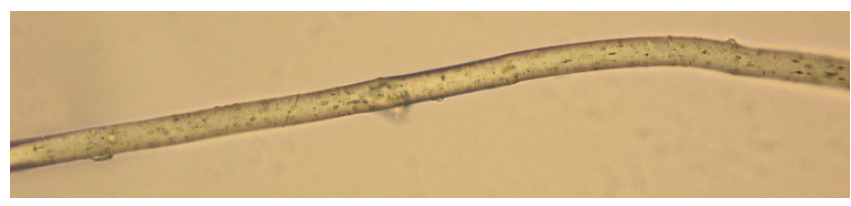

Figure 1. Longitudinal view of polyester fibre.

Yarn settings were calculated according to Ashenhurst $1^{\text {st }}$ theory (31) for the loom state by Equation (1)

$S=F_{w} K \sqrt{N}$

where $F_{w}$ is weave factor, $K$ is coefficient based on yarn type and count, $N$ is yarn count and then determined among the calculations practically within the weaveability limits of the sampling loom. Warp and weft density of all kinds of woven fabric specimens on the loom were 10 yarn per cm. Any finishing process was not applied to the fabric specimens. 


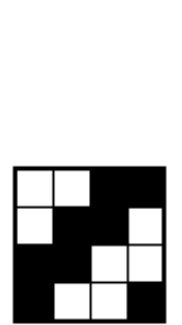

(a)

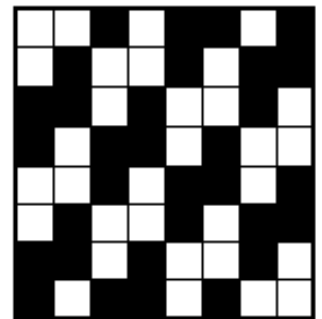

(b)

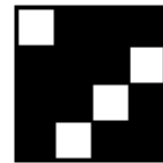

(c)

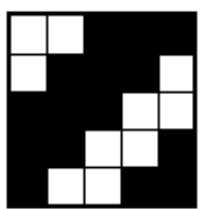

(d)

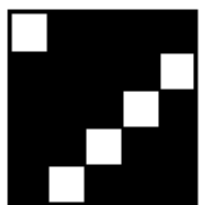

(e)

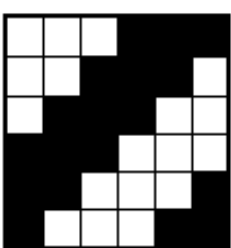

(f)

Figure 2. Weave patterns used in experimental: (a) $2 / 2$ twill weave, (b) $2 / 2$ broken twill, (c) 3/1twill weave, (d) 3/2twill weave, (e) 4/1twill weave, (f) $3 / 3$ twill weave.

All weaves except for broken twill are square weaves, so the number of each warp and weft yarn interlacing is equal to each other. And also the average float length of warp yarn is equal to the average float length of weft yarn. The average float length $F$ was calculated according to Ashenhurst (31) by Equation (2);

$F_{1 / 2}=\frac{R_{2 / 1}}{t_{1 / 2}}$

where $R_{2 / 1}$ is the weft (2) or warp (1) repeat, and $t_{1 / 2}$ the number of warp or weft intersections in weave repeat. Subscripts 1 and 2 are used throughout to denote warp and weft respectively. The other fabric property, the weave interlacing coefficient, defined by Galcerán (32) was calculated by Equation (3);

$$
K L=\frac{i}{w_{1} \times w_{2}}
$$

where $i$ is the number of interlacing points in weave repeat, $w_{1}$ is the number of ends in weave repeat $w_{2}$ is the number of picks in weave repeat.

On the other hand, 2/2 broken twill weave is not square unit weave, namely unbalanced weave, thus the average float length of warp yarn is different from the average float length of weft yarn as given in Table 2. Furthermore the number of warp yarns interlacing is not equal to that of weft yarns interlacing, so; the warp yarn interlacing coefficient is not equal to weft yarn interlacing coefficient, calculated by Equation (4)

$$
\text { yic }_{1 / 2}=\frac{i_{1 / 2}}{w_{2 / 1}}
$$

where $i_{1 / 2}$ is the number of warp or weft interlacing points in weave repeat, $w_{2 / 1}$ is the number of picks or ends in weave repeat. And also, the average float length of warp yarns is different from that of weft yarns as given in Table 2.

\subsection{Production of composites}

Composite plates were manufactured by vacuum-assisted resin infusion process (33). Above mentioned woven fabrics were used as reinforcements and Huntsman Araldite LY 1564 epoxy with its hardener Aradur 3486 were used as resin. The mixing ratio of the epoxy to the hardener was $3: 1$ by weight. Four square fabrics of $42 \times 42 \mathrm{~cm}$ dimensions were placed in the same warp and weft directions on a flat mould. All the materials were packaged and resin was infused under the vacuum as 1 bar. Composite specimens were cured at $80{ }^{\circ} \mathrm{C}$ for $8 \mathrm{~h}$. After removing the infusion residual materials the composite plates were cut into the specimen dimensions of $25 \times 200 \mathrm{~mm}$. The codes used for carcass fabric specimens were also used for definition of the composites specimens. The fibre volume fraction values and the thicknesses of the composites are given in Table 3.

Photographs of composite specimens were taken in succession along the yarn by a Sony TRV 40E digital video camera with a resolution of 1.39 megapixels. The digital video camera was arranged to automatic focus mode. The digital video camera was assembled on a video recording platform on which it could be moved in the vertical direction.

Table 1. The specifications of carcass fabrics.

\begin{tabular}{|c|l|c|c|c|c|}
\hline $\begin{array}{c}\text { Carcass } \\
\text { fabric code }\end{array}$ & \multicolumn{1}{|c|}{ Weave pattern } & $\begin{array}{c}\text { Warp density } \\
\text { on the reed }\end{array}$ & $\begin{array}{c}\text { Weft density } \\
\text { on the loom }\end{array}$ & $\begin{array}{c}\text { The weave interlacing } \\
\text { coefficient }\end{array}$ & $\begin{array}{c}\text { The average float } \\
\text { length }\end{array}$ \\
\hline A & 2/2 Twill & 10 & 10 & 0,5 & 2 \\
\hline B & 2/2Broken twill & 10 & 10 & - & - \\
\hline C & 3/1 Twill & 10 & 10 & 0,5 & 2 \\
\hline D & 3/2 Twill & 10 & 10 & 0,4 & 2,5 \\
\hline E & 4/1Twill & 10 & 10 & 0,4 & 2,5 \\
\hline F & 3/3 Twill & 10 & 10 & 0,33 & 3 \\
\hline
\end{tabular}

Table 2. The specifications of $2 / 2$ broken twill woven fabric.

\begin{tabular}{|c|c|c|c|c|}
\hline Weave pattern & $\begin{array}{c}\text { The average float } \\
\text { length of warp yarn }\end{array}$ & $\begin{array}{c}\text { The average float length } \\
\text { of weft yarn }\end{array}$ & $\begin{array}{c}\text { The warp yarn } \\
\text { interlacing coefficient }\end{array}$ & $\begin{array}{c}\text { The weft yarn } \\
\text { interlacing coefficient }\end{array}$ \\
\hline 2/2 Broken twill & 2 & 1,33 & 0,5 & 0,75 \\
\hline
\end{tabular}


Table 3. The fibre volume fraction values and the thicknesses of the composites.

\begin{tabular}{|c|c|c|}
\hline Specimen & Thickness $(\mathbf{m m})$ & Fibre volume fraction (\%) \\
\hline A & 4.35 & 69 \\
\hline B & 4.27 & 70 \\
\hline C & 4.23 & 70 \\
\hline D & 4.05 & 71 \\
\hline E & 3.99 & 71 \\
\hline F & 3.91 & 72 \\
\hline
\end{tabular}

\subsection{Tensile Strength Test}

Modulus of elasticity, tensile strength and ultimate tensile strain values of composite plates were determined according to ASTM D3039/3039M 14 (34).

The composite plate was cut into the tensile specimen sizes according to the related standard. The warp and weft directions of the specimen are the two principal material directions. The tensile tests were carried out by using Universal Shimadzu AG-X testing machine, having a loading capacity of $100 \mathrm{kN}$, at a crosshead speed of $2 \mathrm{~mm} / \mathrm{min}$ as shown in Figure 3. Five specimens were used for each test type and each material directions, and all of the specimens were loaded up to rupture. As the specimens used in this study were broken as brittle manner, in other words, the cross section area at the broken section of the specimen and the initial cross section area were nearly the same; the tensile strength value was calculated by dividing the ultimate force to the initial cross-sectional area of the specimen. A video extensometer device was used to obtain the strain values. Markers on two stickers stuck on the specimen were constantly tracked in the captured video images (Figure 3). Strain values were calculated by dividing the increase of the distance between the markers to the initial distance between them. The stress-strain curves of the specimen drawn by a software installed into a computer connected to the tensile testing machine.

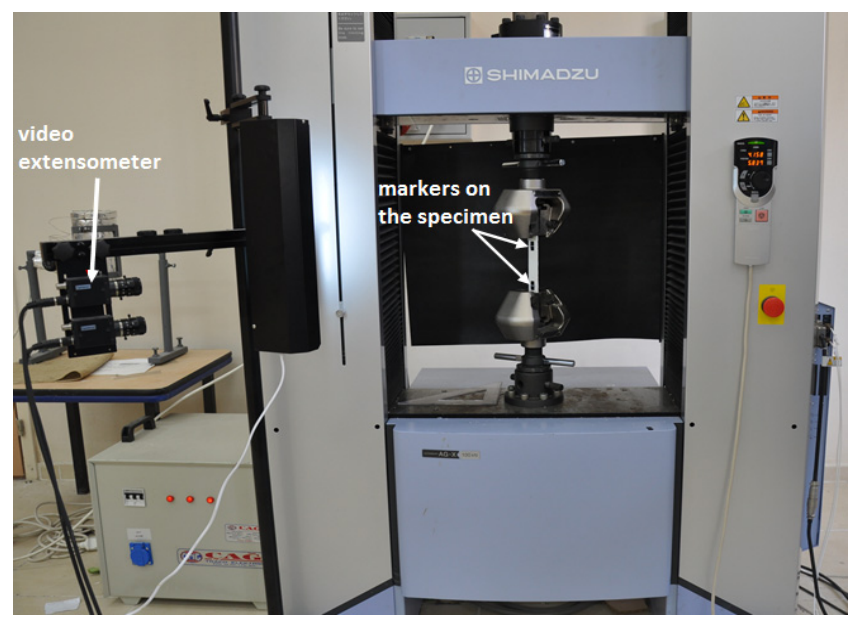

Figure 3. Tensile testing machine.

\subsection{Determination of Impact Behaviour}

Impact behaviour of the composite plates were determined by using Fractovis Plus impact testing machine. The software used by impact testing machine was capable of calculating time dependent velocity, deflection and absorbed energy values from load history given by force transducer. The impact testing machine used in this study was suitable for a wide variety of applications requiring low to high impact energies with the assistance of adding mass and (or) adjusting velocity. The impactor has a hemispherical nose with $12.7 \mathrm{~mm}$ diameter. The impactor is connected to a force transducer which has a maximum loading capacity of $22.4 \mathrm{kN}$. The total impact mass including impactor nose, force transducer and crosshead was $4.926 \mathrm{~kg}$. The specimens were fixed by a pneumatic fixture with a $76.2 \mathrm{~mm}$ hole diameter as shown in Figure 4. Impact tests were performed at several impact energies: $15 \mathrm{~J}, 20 \mathrm{~J}, 25 \mathrm{~J}, 30 \mathrm{~J}$, $35 \mathrm{~J}$ and $40 \mathrm{~J}$, which were applied to the different specimens. One specimen was tested for each case.

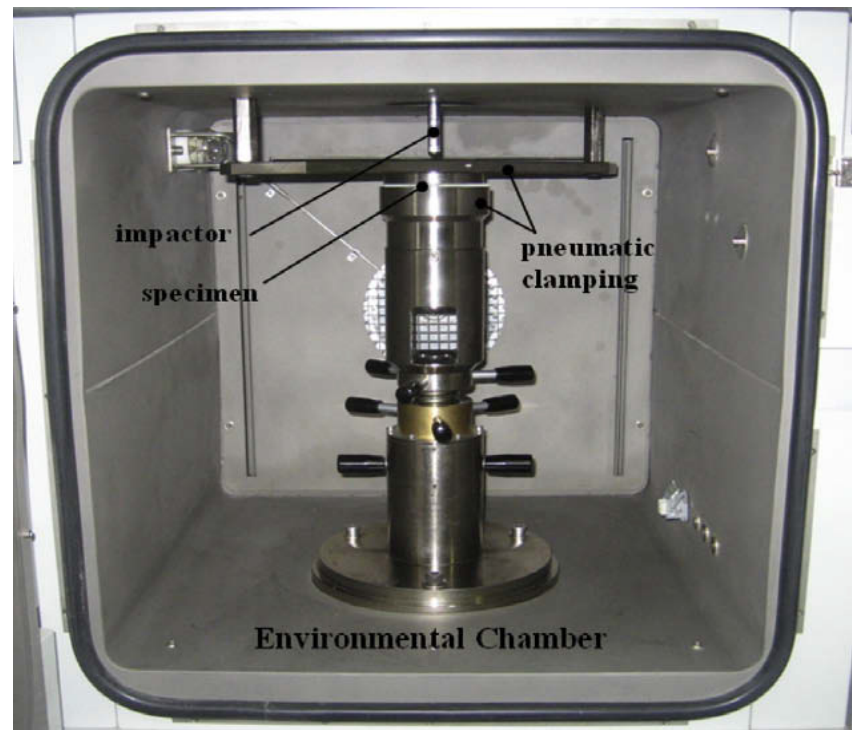

Figure 4. Impact test fixture

\section{RESULTS AND DISCUSSIONS}

Test results for composite specimens were evaluated statistically by Analysis of Variance (ANOVA) according to the General Linear Model with SPSS 15.0 software package. In order to analyse the effect of weave pattern, Multivariate Analysis was made for all specimens. Significance degrees ( $p)$, given in Table 4, which were obtained from ANOVA, were compared with significance level $(\alpha)$ of 0.05 . The effects, whose significance degrees were lower than 0.05 , were interpreted as statistically important (35).

\subsection{Tensile Properties}

Stress-strain curves of the composite specimens with warp and weft directions are shown in Figure 5. One for each type of material and material direction were selected among the five tested specimens, and presented in this figure. The stress-strain curves of these specimens increases linearly and then keeps increasing non-linearly up to the maximum stress point. The gradient of the linear region of the stressstrain curve gives the value for elasticity modulus of the material. The last data for each curve gives the tensile strength and elongation at break values. 
Table 4. The results of ANOVA for the effect of weave pattern on the tensile and impact properties of composites

\begin{tabular}{|c|c|c|c|c|c|c|}
\hline Source & Dependent Variable & $\begin{array}{l}\text { Type III Sum of } \\
\text { Squares }\end{array}$ & df & Mean Square & $\mathrm{F}$ & Sig. (p) \\
\hline \multirow[t]{9}{*}{ Weave } & Elasticity modulus along warp direction & 22725442.170 & 5 & 4545088.433 & 182.016 & .000 \\
\hline & Elasticity modulus along weft direction & 18797701.870 & 5 & 3759540.373 & 59.393 & .000 \\
\hline & Tensile strength along warp direction & 508.667 & 5 & 101.733 & 12.534 & .000 \\
\hline & Tensile strength along weft direction & 435.867 & 5 & 87.173 & 7.526 & .000 \\
\hline & Elongation at break along warp direction & 45.693 & 5 & 9.139 & 10.129 & .000 \\
\hline & Elongation at break along weft direction & 21.745 & 5 & 4,349 & 4.015 & .009 \\
\hline & Impact bending stiffness & 26364.467 & 5 & 5272.893 & 31.225 & .000 \\
\hline & Peak force & 442394.519 & 5 & 88478.904 & 5.654 & .001 \\
\hline & Maximum deflection & 3.170 & 5 & .634 & 29.032 & .000 \\
\hline
\end{tabular}
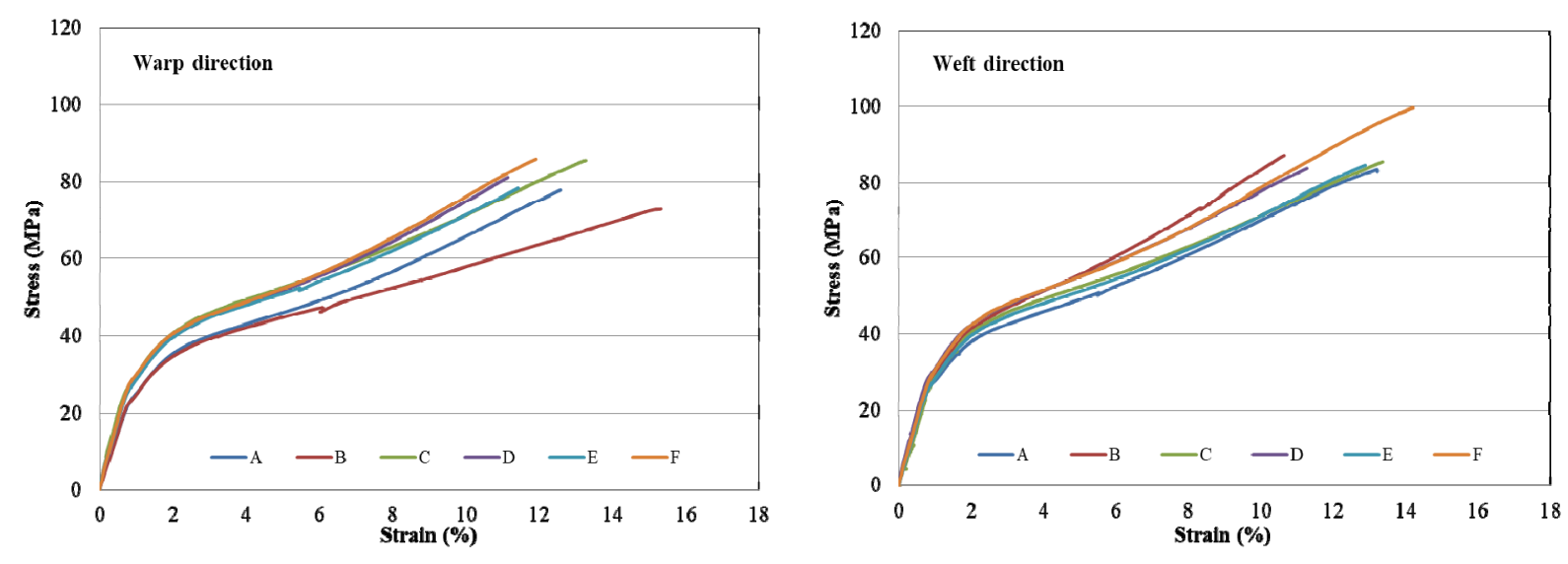

Figure 5. Stress-strain curves of specimens

Modulus of elasticity values of the composite specimens along warp and weft directions are given in Figure 6 . It is seen that, specimens $C, D, E$ and $F$, reinforced with $3 / 1,3 / 2$, $4 / 1$ and $3 / 3$ twill woven fabrics respectively, have higher modulus of elasticity in warp direction than specimens $B$ and $A$, reinforced $2 / 2$ broken and $2 / 2$ twill woven fabrics respectively. Because, average float length of $3 / 1,3 / 2,4 / 1$ and $3 / 3$ twill woven fabrics are higher than those of $2 / 2$ broken and $2 / 2$ twill woven fabrics. In $3 / 1,3 / 2,4 / 1$ and $3 / 3$ twill woven fabrics, long portions of yarns come side by side and close up and then they resist much against tensile forces applied in elastic region. Among specimens C, D, E and $F$, the specimen $C$ has the highest elasticity modulus. This is due to the fact that the weave interlacing coefficient of the specimen $C$ is the highest among specimens $D, C, E$ and $F$, namely that the number of interlacing between warp and weft yarns in $3 / 1$ twill woven fabric reinforced the specimen $C$ is the highest. This increase the friction between the warp and weft yarns, consequently, the modulus of elasticity rise.

The modulus of elasticity in weft direction are almost equal to the modulus of elasticity in warp direction for specimens $A, C, D, E$ and $F$. This is because of the fact that $2 / 2,3 / 1$, $3 / 2,4 / 1$ and $3 / 3$ twill weaves are square weaves, in other words; average float length of warp yarns and warp yarn interlacing coefficients are equal to average float length of weft yarns and weft yarn interlacing coefficients respectively for these weaves. The modulus of elasticity of the specimen $B$ in weft direction is higher than that in warp direction. It can be explained by the fact that in 2/2 broken twill woven fabric, the weft yarn interlacing coefficient is bigger than warp yarn interlacing coefficient. This increase the friction between the warp and weft yarns in the intersection areas and then the modulus of elasticity in weft direction increase in elastic region.

From the results of ANOVA, it can be concluded that the effect of weave pattern on the elasticity modulus of composite specimens along warp and weft directions are statistically important at the significance level of 0.05 . Significant of differences are also observed from error bars in graphs that do not intercept with each other.

Tensile strengths of composite specimens along warp and weft directions are shown in Figure 7. It is observed in Figure 7 that the tensile strength values of composite show the same trend with the elasticity modulus values of composites. Composite C, D, E and F have higher tensile strength in both warp and weft directions than those of specimens $B$ and $A$ as for the elasticity modulus in warp and weft directions. This arisen from that long portions of yarns, in $3 / 1,3 / 2,4 / 1$ and $3 / 3$ twill woven fabrics, come side by side and close up and then they resist much against tensile forces applied during tensile tests.

Performances shown by specimens in weft direction are similar to performances in warp direction. Besides, tensile strength of $2 / 2$ broken twill weave in weft direction is higher than that of $2 / 2$ broken twill in warp direction. This is because of the fact that the number of interlacing in weft direction is higher than that in warp direction, namely that the friction in weft direction is higher than that in warp direction. This increase the tensile strength in weft direction. 

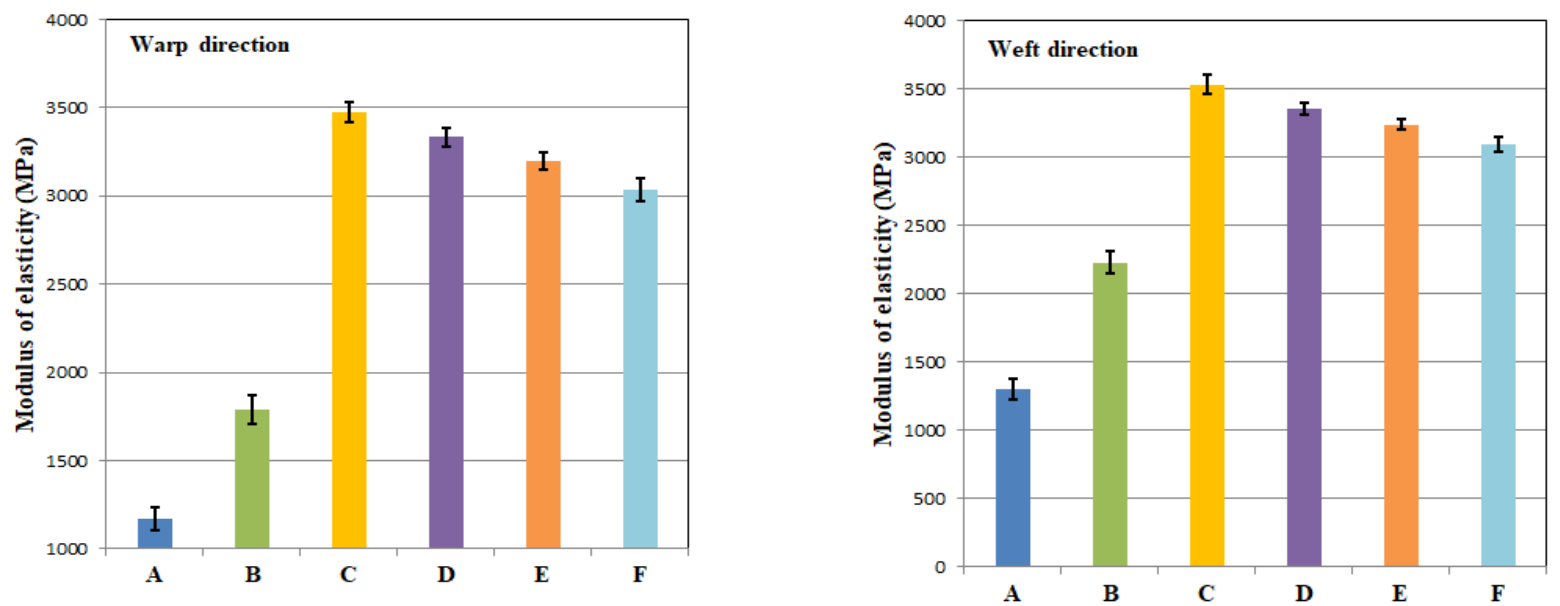

Figure 6. Modulus of elasticity along the warp and the weft directions.
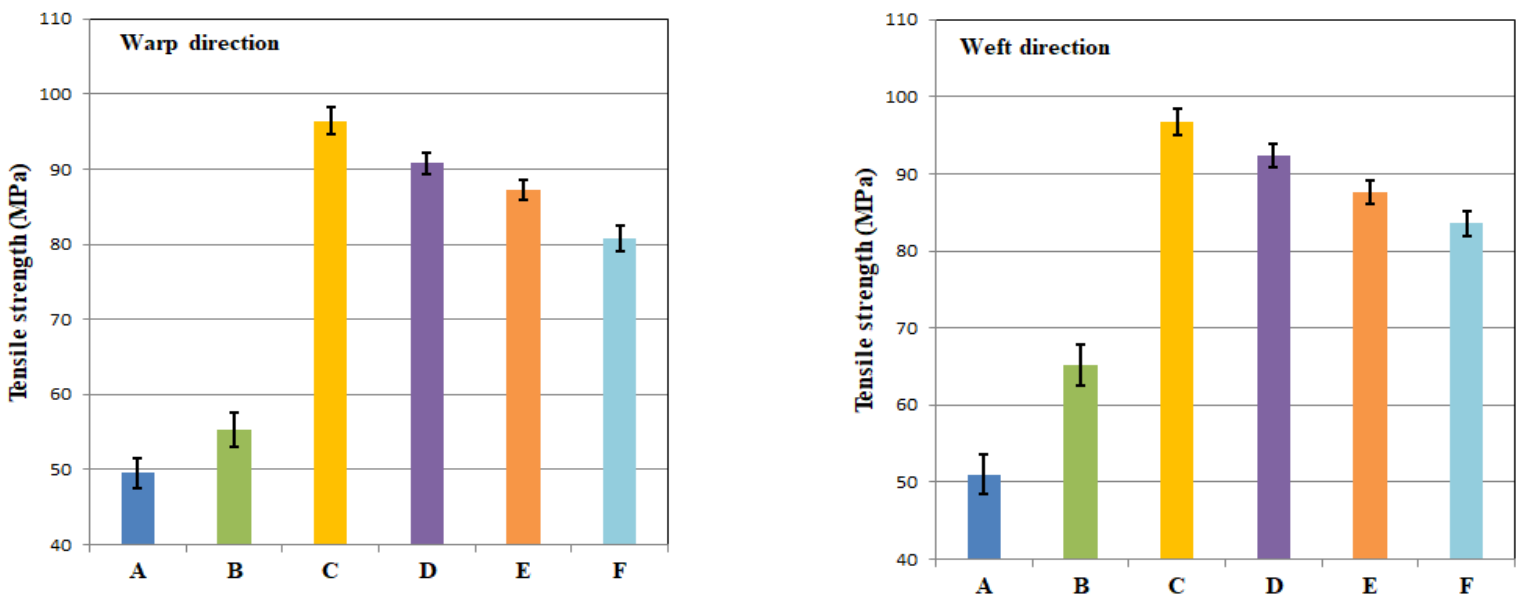

Figure 7. Tensile strengths of the composites along the warp and the weft directions.

From the results of ANOVA, it can be concluded that weave patterns have affected the tensile strengths of composite specimens along warp and weft directions statistically $(\alpha=$ 0.05). Significant of differences are also observed from error bars in graphs that do not intercept with each other.

Elongations at break of composite specimens along warp and weft directions are given in Figure 8 . It is observed in Figure 8 that specimens $C, B$ and $A$ have higher elongation at break values in warp direction than those of specimens $D$, $E$ and $F$. It can be explained by the fact that $3 / 1,2 / 2$ broken and $2 / 2$ twill woven fabrics have higher weave interlacing coefficients that those of $3 / 2,4 / 1$ and $3 / 3$ twill woven fabrics. Therefore; in this fabrics, yarns are more crimped and then more crimped yarns will de-crimp and elongate more during tensile tests. The specimen $C$ has the highest elongation at break values among specimens, reinforced woven fabrics with the highest weave interlacing coefficient. In the specimen $\mathrm{C}$, long portions of yarns get close to each other, resist more and then elongate more amount during tests. The specimen $F$ has the lowest elongation at break value, this is due to the fact that the specimen $F$ has the lowest weave interlacing coefficient, and thus it elongate the least amount during tests. Moreover, elongation at break values of specimens $D$ and $E$ in warp and weft directions are almost equal to each other. Because, 3/2 twill and 4/1 twill woven fabrics, reinforced specimens $D$ and $E$ respectively, have the same weave interlacing coefficient.

Specimens show the similar elongation at break behaviour in weft direction to that in warp direction. Elongation at break values of specimens in weft direction are higher than those in warp direction. This is because of the fact that weft yarns have less tension than warp yarn during weaving, therefore weft yarns elongate more easily than warp yarns during tests. The specimen $B$, reinforced with $2 / 2$ broken twill fabric, elongate the highest amount in weft direction, due to its highest weft yarn interlacing coefficient among specimens.

From the results of ANOVA, it can be concluded that the effect of weave pattern on the elongation at break of composite specimens, along warp and weft directions, are statistically important at the significance level of 0.05 . Significant of differences are also observed from error bars in graphs that do not intercept with each other. 

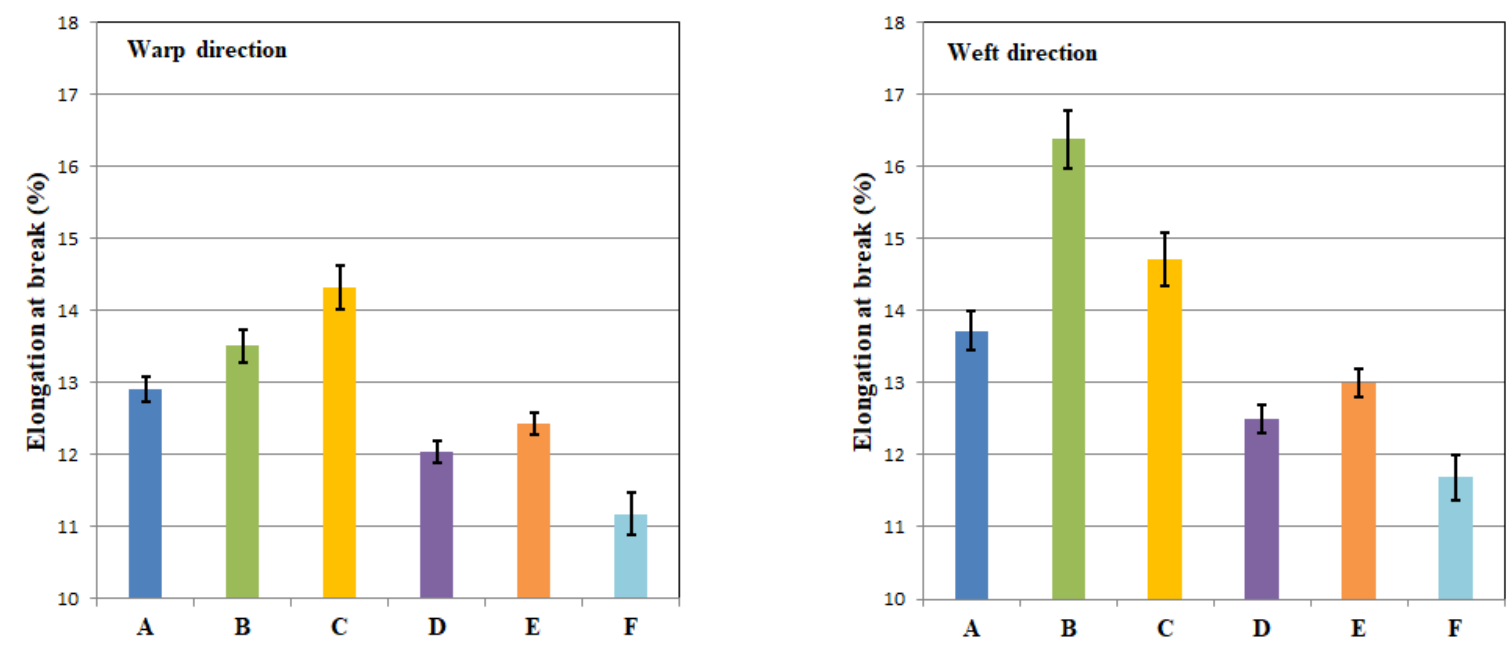

Figure 8. Elongations at break of composites along the warp and the weft directions.

\subsection{Impact Behaviour}

The effects of the weave on the impact characteristics, such as peak force, impact bending stiffness, maximum deflection and absorbed energy are examined. For better understanding, some images of the damaged specimens are also provided.

In this study, the impact energy was gradually increased until perforation took place. Three main types of contact force-deflection curves were seen in Figure 9 (36). Each curves has ascending and descending sections. The slope of the ascending section is named as the impact bending stiffness. Impact bending stiffness is the stiffness of a composite plate under impact-induced bending at the beginning of the impact process. The peak load is defined as the maximum contact force between the impactor nose and the composite plate in an impact event. The maximum deflection is the largest distance between the top surface of the composite specimen that has deflected and its initial position.

The first type of curve in Figure 9a indicates the rebounding case. The curve consists of an ascending section of loading and a descending section combining loading and unloading. The descending section contain partial softening of the specimen and partial rebounding of the impactor. The area enveloped by the closed curve is the absorbed energy by the composite laminate under impact loading. Absorbed energy gives significant hints about the response of composite materials. The absorbed energy is the energy absorbed by the composite specimen for the formation of damage and the friction between the impactor and the specimen. (37-40). Maximum deflection of the composite can be found from the contact force-deflection curves. If the impact energy increases, the composite plate absorbs all of the impact energy and the impactor doesn't rebound from the composite plate. This is the penetration case and the descending section of the curve is completely a softening curve, in other words curve does not have any rebounding section (Figure 9b). The third type of curve shows perforation (Figure 9c). After the descending section the contact force reach a relatively constant value due to the friction between the impactor and the composite specimens after the occurrence of perforation. The absorbed energy of a perforated composite specimen can be calculated from the area between the associated force-deflection curve and the horizontal axis up to the beginning of the friction region of the curve. This absorbed energy value is named as the perforation threshold.

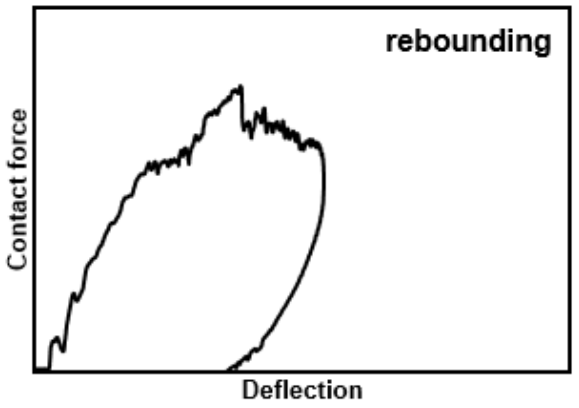

a

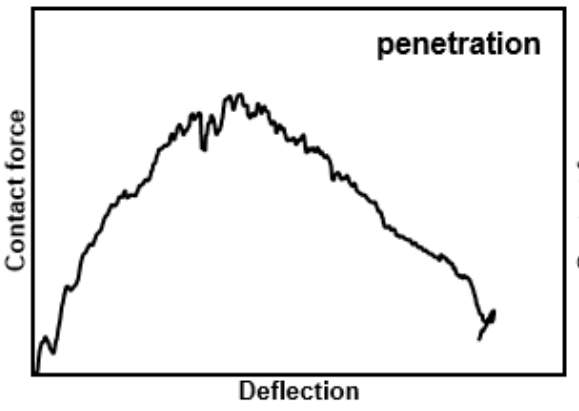

b

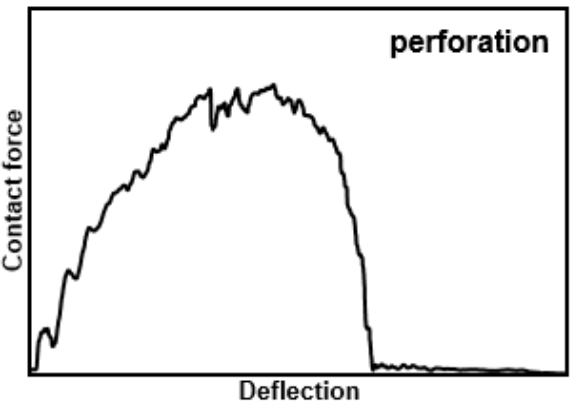

c

Figure 9. Typical load-deflection curves of composites subjected to impact loading (36) 
The contact force deflection curves of composite with six different woven fabrics are given in Figure 10. The codes of the materials are shown in each figure part. For example Figure 10a gives the impact response of the composite reinforced with $2 / 2$ twill woven was coded as $A$. This type of composite was impacted with various energies such as $15 \mathrm{~J}$,
20J, 25J, 30J, $40 \mathrm{~J}$ and $35 \mathrm{~J}$. In the figure each impact energies are shown in different colour. For the same type of materials, the ascending sections of all curves are very similar, showing the consistency of the properties of the composite specimens and the testing conditions involved.

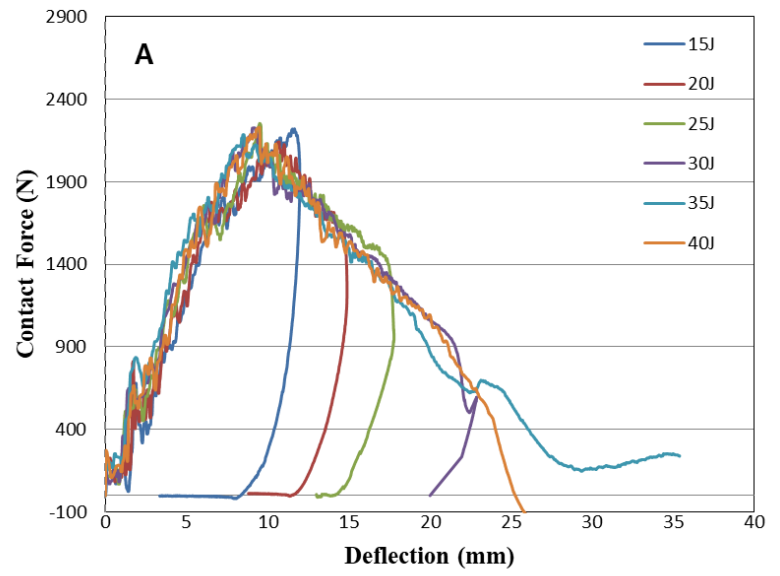

(a)

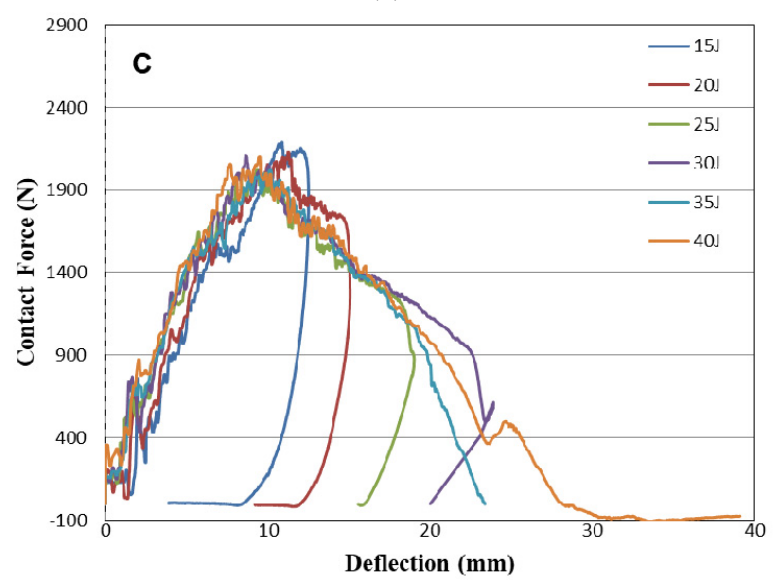

(c)

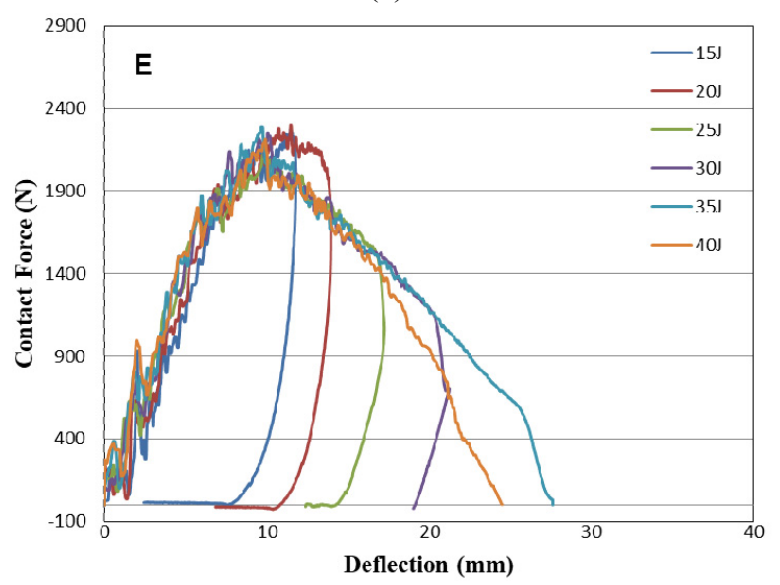

(e)

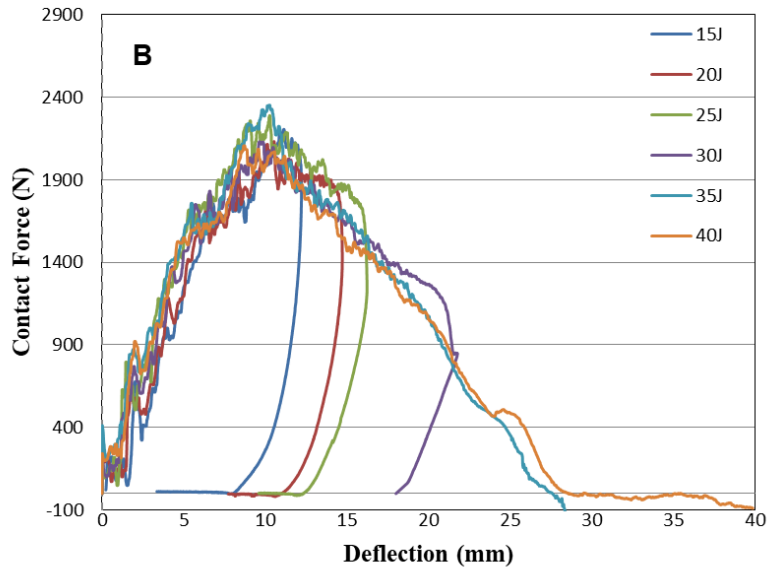

(b)

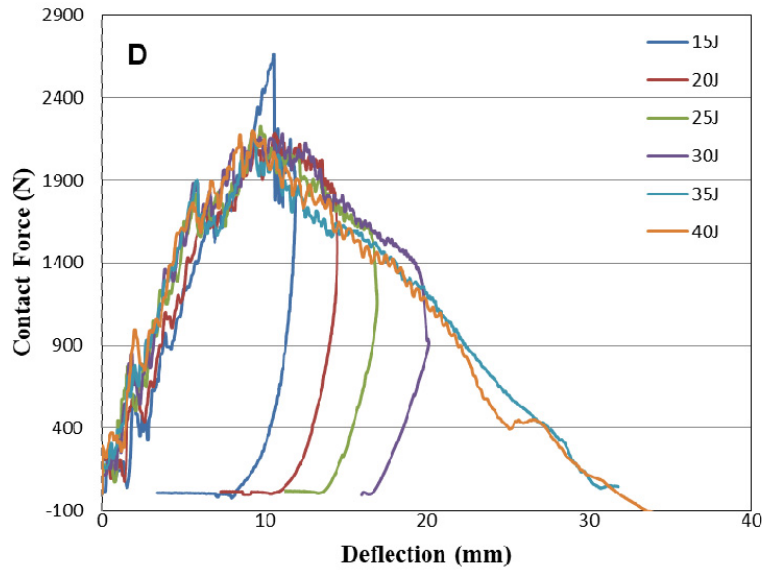

(d)

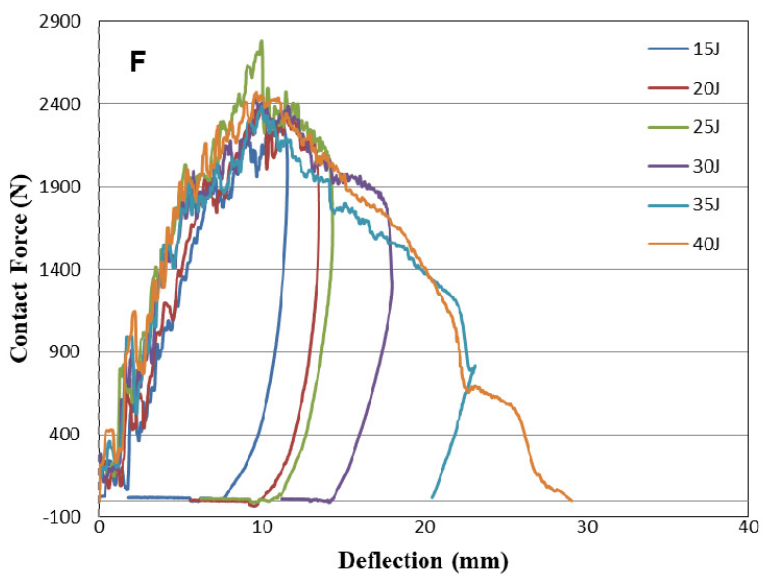

(f)

Figure 10. Contact force-deflection curves of the composites for various impact energy levels 
For lower impact energies, e.g. impact energy, $E_{i}=15 \mathrm{~J}, E_{i}$ $=20 \mathrm{~J}$, and $E_{i}=25 \mathrm{~J}$, all the load-deflection curves seem to show similar loading and unloading sections, containing partial softening of the specimen and partial rebounding of the impactor. As the impact energy increases to $E_{i}=30 \mathrm{~J}$, for the specimen $B, D$, and $F$ rebounding took place, resulting in partial softening and partial rebounding, while, penetration took place for the specimen $A, C$, and $E$. Whereas, when the impact joule is increased $E_{i}=35 \mathrm{~J}$, except specimen $F$, perforation took place for all specimens. As the impact energy continues to increase, e.g. $E_{i}=40 \mathrm{~J}$, it can be observed that all specimens were perforated. Because all curves are the open type. Rebounding by the energies up to $30 \mathrm{~J}$ can be explained by the fact that yarns align diagonally in twill woven fabrics, thus they slip over each other and yield diagonally when the impact forces applied. From these curves some impact characteristics such as impact bending stiffness, peak force and absorbed energy by composite were found.

In order to find the slope of the ascending section (impact bending stiffness) linear regression process was applied and R-squared values were also found. For all curves Rsquared values were higher than 0.95. Impact bending stiffness values are given in Figure 11a. As can be seen in this figure, the specimen $C$ has the lowest impact bending stiffness, while the specimen $F$ has the highest. This means that if all the specimens loaded with the same force, the specimen $\mathrm{F}$ has the lowest deflection value while $\mathrm{C}$ has the highest deflection. In $3 / 1$ twill weave, floating portions of the warp yarns are interlaced with only one weft yarn. In the same way, floating weft yarns in back face are interlaced with only one warp yarn, therefore the specimen $\mathrm{C}$ deforms easily. And also, 3/1 twill weave has higher weave interlacing coefficient than those of $3 / 2,4 / 1$ and $3 / 3$ weaves, namely warp and weft yarns have higher crimp in weave structure, therefore the specimen $\mathrm{C}$ will be deformed at the highest deformation. $3 / 3$ twill weave has the lowest yarn interlacing coefficients, in a word, warp and weft yarns have the lowest crimp in weave structure, for this reason the specimen $\mathrm{F}$ deformed at the lowest deflections.

From the results of ANOVA, it can be concluded that the effect of weave pattern on the impact bending stiffness of composite specimens along warp and weft directions are statistically important at the significance level of 0.05 . Significant of differences are also observed from error bars in graphs that do not intercept with each other.

The mean peak force values and standard deviation values were calculated and are shown in Figure 11b. As can be seen in this figure, the specimen $C$ has the lowest peak force value, while the specimen $F$ have the highest. This result is similar with impact bending stiffness results given in Figure 11a. This is due to the fact that the average float length of the specimen $F$ is the highest and also in the specimen $F$ reinforced with $3 / 3$ twill woven fabric, long length of warp and weft yarns located diagonally side by side, thus these yarns resist most against forces applied during the impact tests. On the other hand, in 3/1 twill weave, floating portions of warp yarns bound with only with weft yarn, likewise, floating weft yarns in back face bound with only one warp yarn. These connections cannot resist much to impact forces. And also, 3/1 twill woven fabric which reinforced the specimen $\mathrm{C}$, has lower average float length, therefore these short warp and weft yarn floats resist least against forces applied during the impact tests.

From the results of ANOVA, it can be concluded that weave patterns have affected the peak force of composite specimens along warp and weft directions statistically $(\alpha=$ 0.05 ). Significant of differences are also observed from error bars in graphs that do not intercept with each other.

At low impact energies, i.e. $15 \mathrm{~J}$ and $20 \mathrm{~J}$, the maximum deflection values were found from the contact forcedeflection curves and are shown in Figure 11c. The specimen $\mathrm{C}$ subjected to $15 \mathrm{~J}$ impact energy has highest deflection value while the specimen $\mathrm{F}$ has the lowest value. The results of the experiments performed 20J has the similar trend with $15 \mathrm{~J}$. Again, the specimen $\mathrm{C}$ subjected to $20 \mathrm{~J}$ impact energy has highest deflection value while the specimen $F$ has the lowest deflection value. In 3/1 twill weave, floating portions of the warp yarns are interlaced with only one weft yarn. In the same way, floating weft yarns in back face are interlaced with only one warp yarn, hence, the specimen $C$ deformed easily. In addition to this, $3 / 1$ twill woven fabric have higher weave interlacing coefficient than those of $3 / 2,3 / 1$ and $3 / 3$ twill woven fabrics, namely it has higher crimp. Due to these reasons, the specimen $C$ has the maximum deflection during impact test. On the other hand, the specimen $F$ reinforced with $3 / 3$ twill woven fabric have the lowest weft yarn interlacing coefficient that is to say it has lowest crimp, thus the specimen $F$ has the minimum deflection during impact test.

From the results of ANOVA, it can be concluded that the effect of weave pattern on the maximum deflection of composite specimens along warp and weft directions are statistically important at the significance level of 0.05 .

Variation of the absorbed energy $\left(E_{a}\right)$ versus impact energy $\left(E_{i}\right)$, called as energy profile diagram $(17,19)$ is given in Figure 12. It is a useful graphic for understanding of the overall energy absorption process in an impact event. Using with the energy profiling method, it becomes possible to characterize some impact properties such as pure elastic limit, penetration and perforation thresholds (9). The diagonal line in the diagram is the equal energy represents the impact energy is equal to the absorbed energy.

In Figure 12, a variation of the absorbed energy versus impact energy called as energy profile diagram is given. The energy profile is a utility method for understanding the overall energy absorption process in an impact event. The diagonal line is defined as an equal energy line. Differences between equal energy line and the data point are termed as excessive energy. The excessive energy is the energy retained in the impactor and used to rebound the impactor from the specimen at the end of the test. When the penetration occurred the excessive energy becomes zero. In some cases, the threshold of perforation in thin structures cannot be determined. The perforation thresholds for A, B, C, D, E, and F are approximately calculated as $34.8,29.6$, $29.8,34.9,35$ and $40.0 \mathrm{~J}$ respectively. The maximum impact energy to perforate the specimen $C$ is minimum, while $F$ is maximum. The reasons explained for $C$ and $F$ (Figure 11) are valid here. 


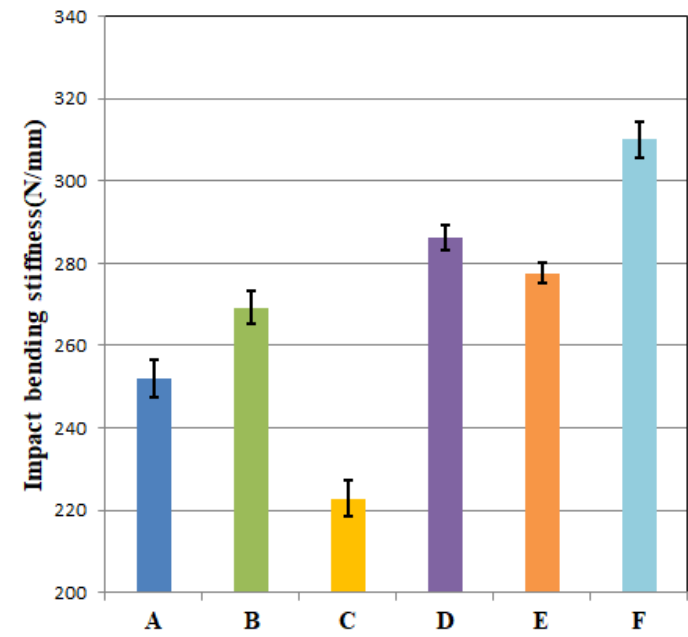

(a)

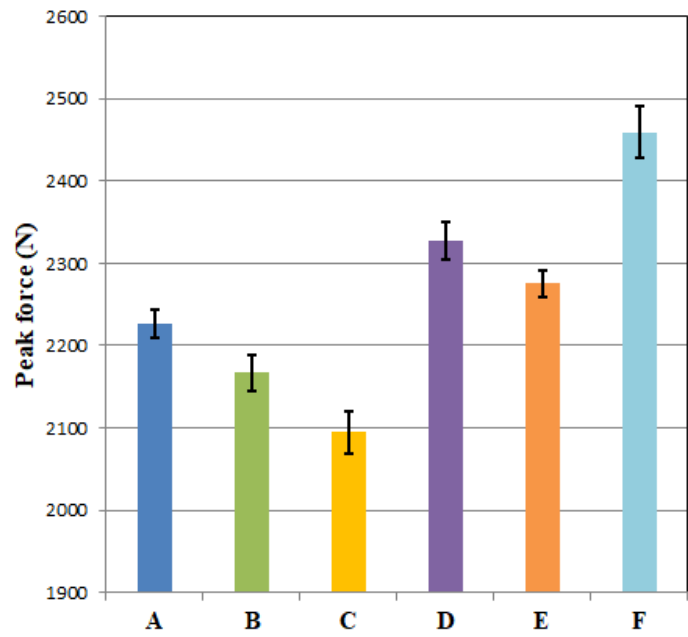

(b)

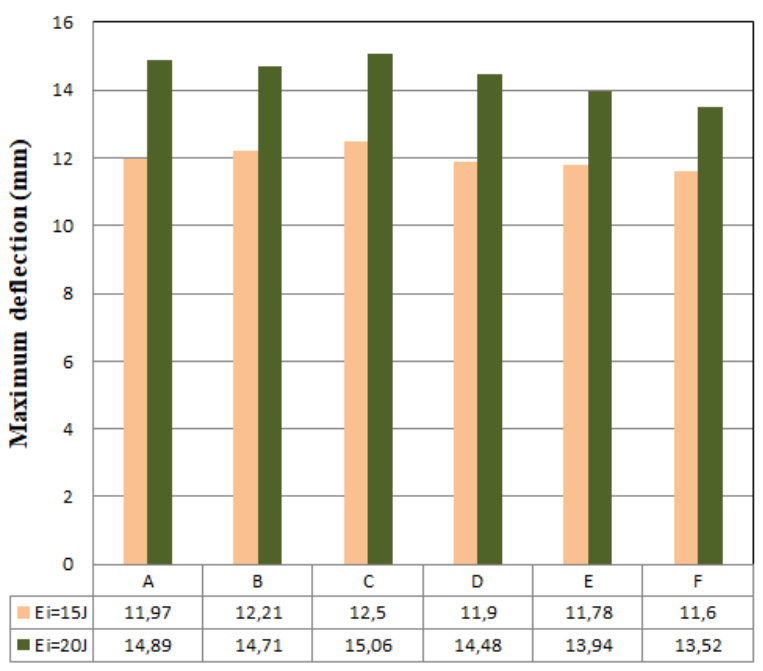

(c)

Figure 11. a) Impact bending stiffness, b) peak force, c) maximum deflection at low impact energies, values of composite plates impacted

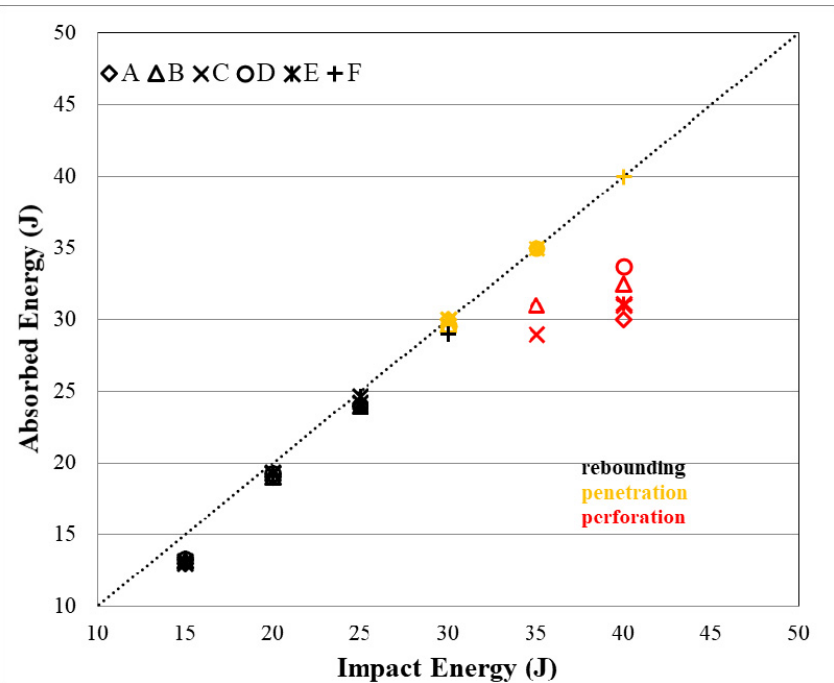

Figure 12. Energy profile diagrams of the composite plate with various woven pattern
The damage modes and the damage sizes of the composite plates change depending on the impact energy. Figure 13 gives the images of the specimen A for the rebounding (25 $\mathrm{J})$, penetration $(35 \mathrm{~J})$ and perforation $(40 \mathrm{~J})$ cases. The photos focused on the impacted point taken from the impacted and nonimpacted rear faces of the composite. In all of these figures, while vertical direction indicates the warp direction, horizontal direction indicates the weft direction. At low impact energy such as $25 \mathrm{~J}$, there are matrix crushing, matrix cracking, fibre breakage and delamination in the composite. The contact force deflection curve shown in Figure $10 \mathrm{a}(25 \mathrm{~J})$ has some fluctuation in ascending section and descending section in consequence of occurrence these failures. Once fibre breakages happened through to thickness, the contact force value decreased suddenly. After this point, the descending section started. At higher impact energy such as $35 \mathrm{~J}$, through to thickness fibre breakages are seen clearly in Figure 13c-d. The perforated specimen impacted at $40 \mathrm{~J}$ are also given in Figure 13e-f. 
In order to see the failure differences between all of the composite specimens impacted at the same impact energy $(E i=40 \mathrm{~J})$ Figure 14 were presented. The photos focused on the impacted point taken from the non-impacted faces of the composites. While vertical direction indicates the warp direction, horizontal direction indicates the weft direction. Two types of failure pattern are observed: symmetric and asymmetric. Symmetric type is the failure occurred along the warp and the weft directions of the woven fabrics. All of the specimens except for the specimen B are symmetric type failure under high impact energies as shown in Figure $14 a, c-f$. The failure type of the specimen $B$ is asymmetric as shown in Figure 14b. 2/2 Broken twill is not a square weaves, namely unbalanced weave, thus the number of warp yarns interlacing is not equal to that of weft yarns interlacing, for this reason the specimen $B$ reinforced with $2 / 2$ broken twill woven fabric resisted in irregular way to the impact forces during the test.

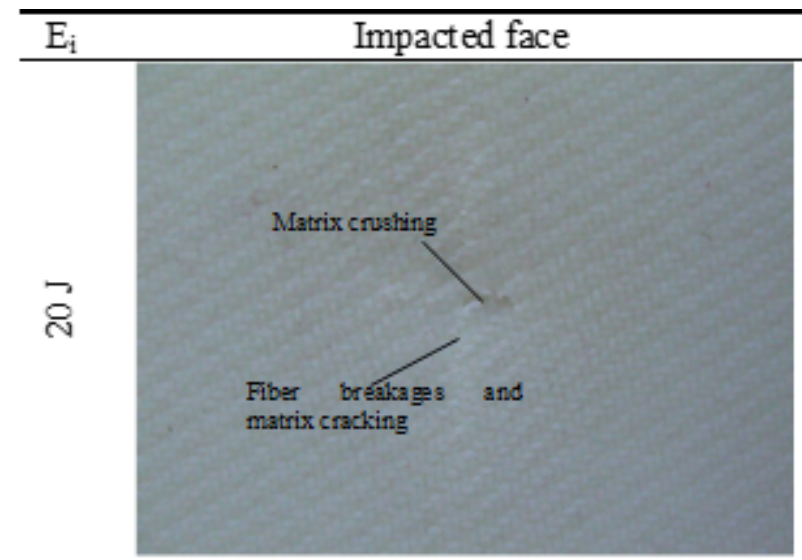

(a)

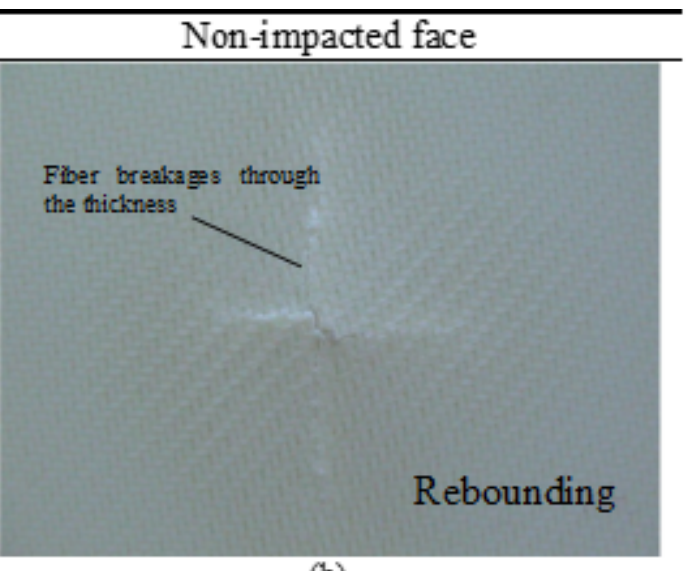

(b)

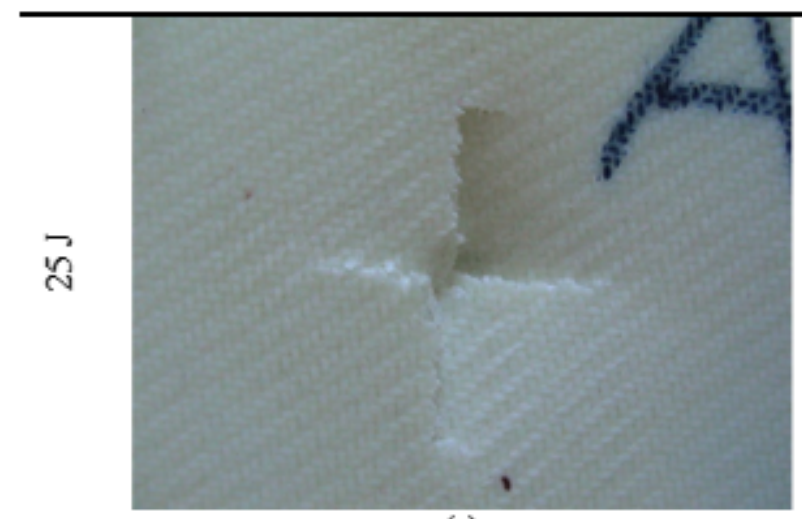

(c)

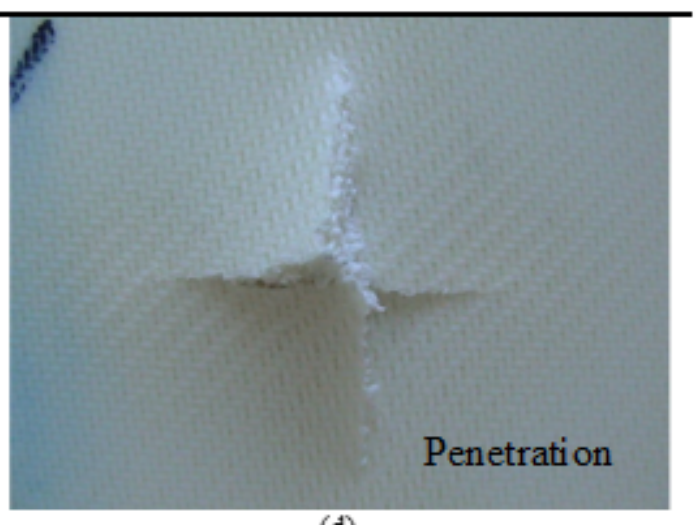

(d)

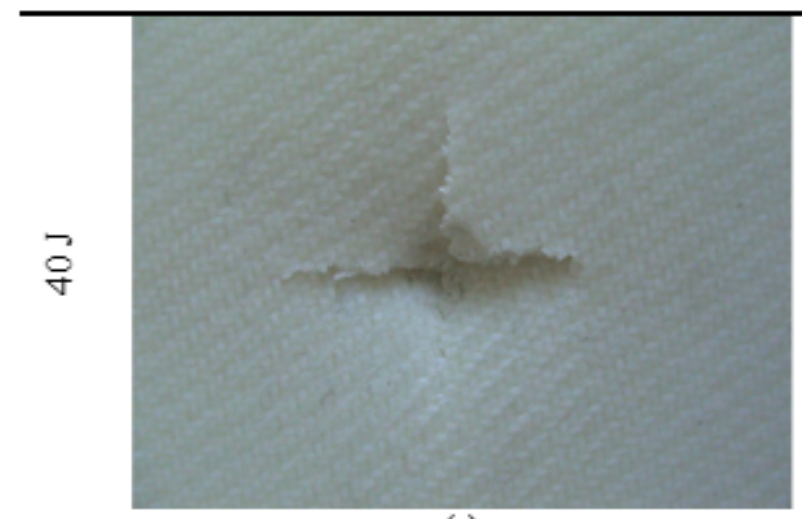

(e)

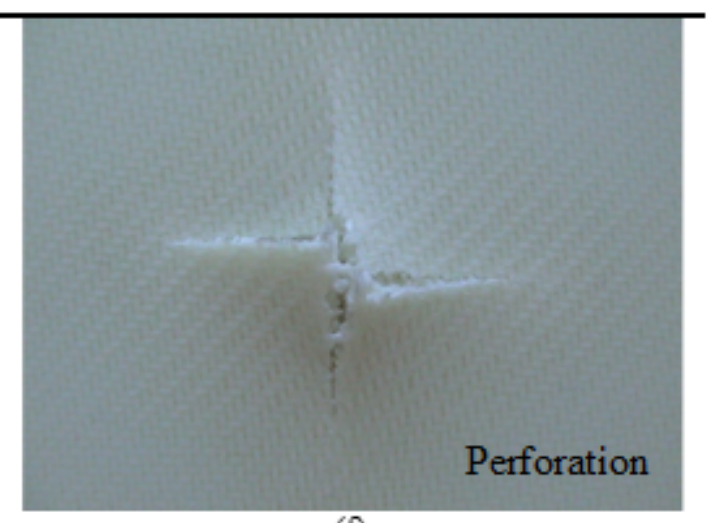

(f)

Figure 13. Images of the specimens A for various impact energies: a-b) rebounding case, c-d) penetration case, e-f) perforation case 


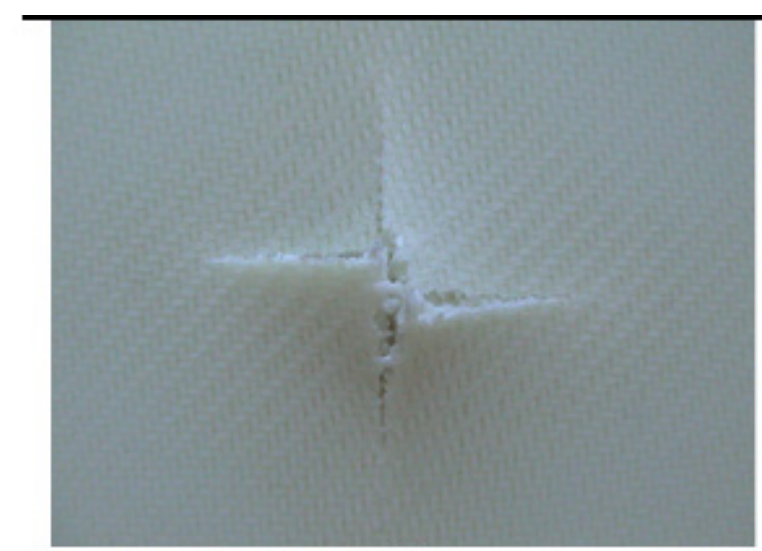

(a)

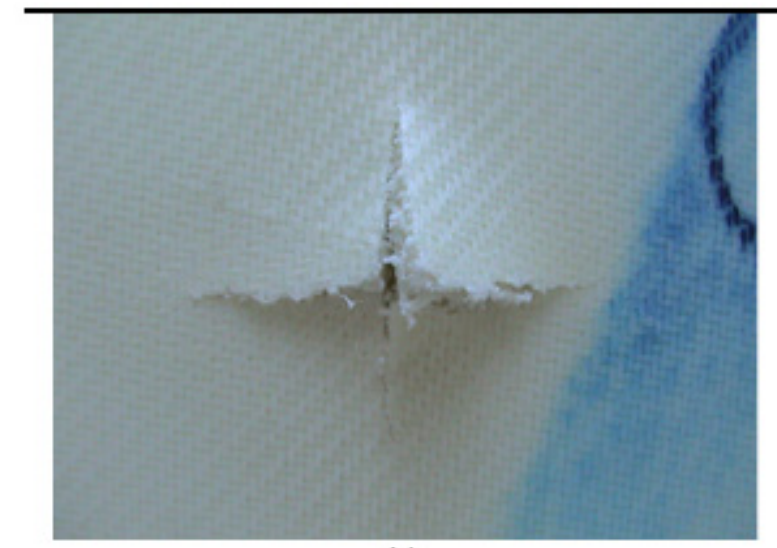

(c)

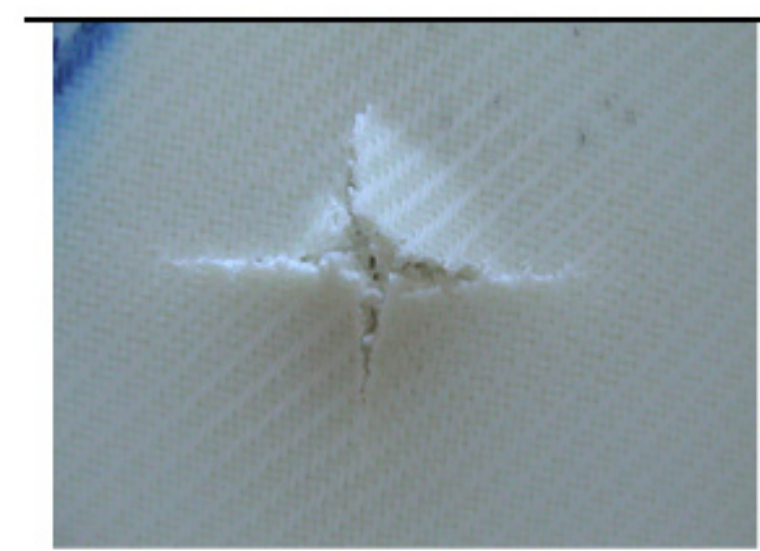

(e)

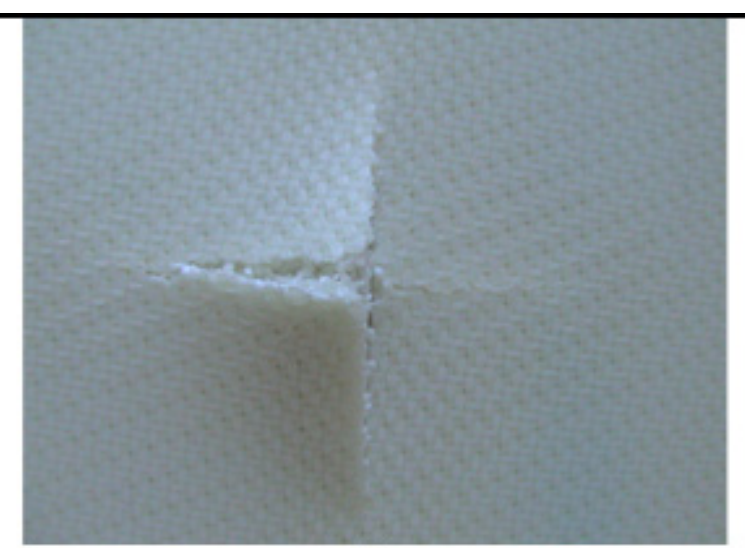

(b)

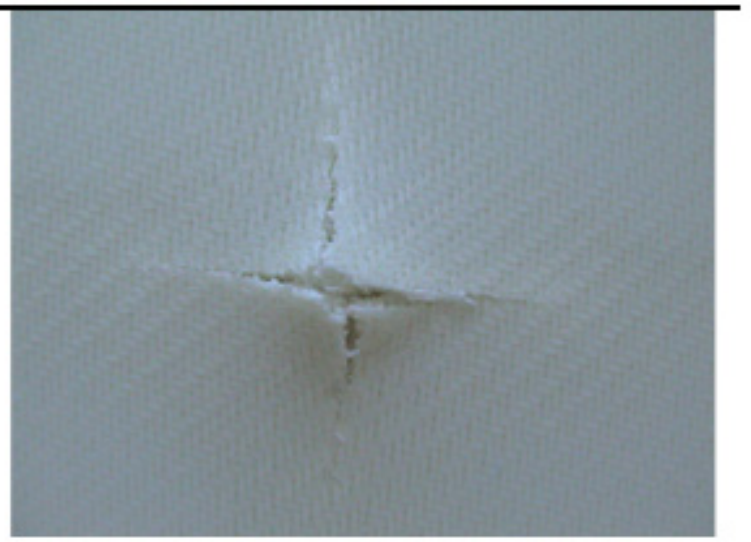

(d)

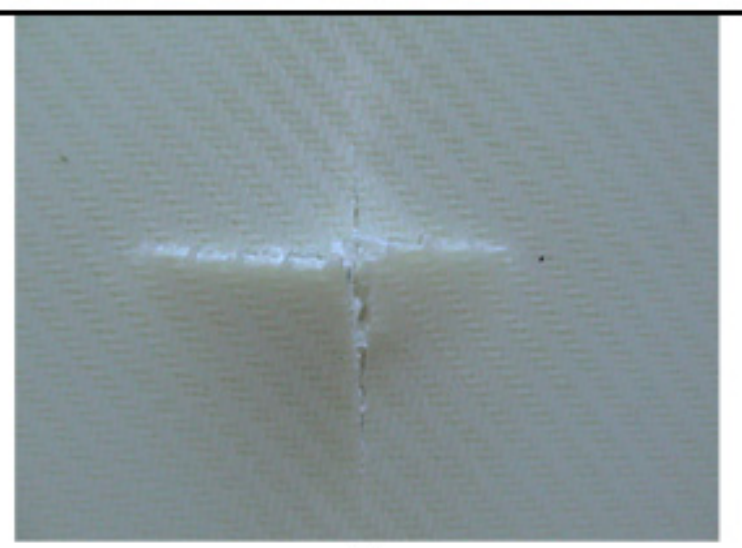

(f)

Figure 14. Images of perforated specimens for impact energy of $40 \mathrm{~J}$ : a) specimen $\mathrm{A}, \mathrm{b}$ ) specimen $\mathrm{B}, \mathrm{c})$ specimen $\mathrm{C}, \mathrm{d}) \mathrm{specimen} \mathrm{D}, \mathrm{e})$ specimen $E$, f) specimen $F$

\section{CONCLUSIONS}

The behaviour of twill and twill derivative woven polyester/epoxy composite has been studied for in-plane tensile loading cases in the warp and weft directions. Six of the most common woven fabrics including $2 / 2$ twill weave, $2 / 2$ broken twill, $3 / 1$ twill weave, $3 / 2$ twill weave, 4/1 twill weave, $3 / 3$ twill weave were considered as the reinforcement phase of the laminated composites. And also, in order to investigate the weave and impact energy effects on the impact characterization of laminated composite plates, impact tests were performed at several impact energies: $15 \mathrm{~J}, 20 \mathrm{~J}, 25 \mathrm{~J}, 30 \mathrm{~J}, 35 \mathrm{~J}$ and $40 \mathrm{~J}$. All specimen rebounded by the energies up to $30 \mathrm{~J}$, due to the diagonally arranged yarns in twill woven fabrics.

It is observed that elasticity modulus of composites is coincident with the tensile strength of those. The weave determines the floating and interlacing of warp and weft yarns with each other in fabric structure, therefore it affects tensile properties of fabrics and also of composites which are reinforced with these fabrics.3/1,3/2, 4/1 and $3 / 3$ twill 
woven fabric reinforced composites, whose average float lengths are high, have high modulus of elasticity and tensile strength values. Among these composites, 3/1 twill woven fabric reinforced composite, whose weave interlacing coefficient is the highest, has the highest modulus of elasticity and tensile strength values. 3/1 twill, 2/2 broken twill and 2/2 twill fabric reinforced composites, whose weave interlacing coefficient are high, elongated more during tensile tests. Besides, the $2 / 2$ broken twill fabric, whose weft interlacing coefficient is higher than that of warp interlacing coefficient, reinforced composite elongated more in weft direction than in warp direction.

The type of woven fabric, which determines the average float length of yarn and weave interlacing coefficient, that are important factors, affected the response of the composite subjected to the impact loading. In $3 / 3$ twill woven fabric, long length of warp and weft yarns located diagonally side by side, therefore $3 / 3$ twill woven fabric reinforced composite resisted most against forces applied during impact loading. The specimen $\mathrm{F}$ has the highest peak force and impact bending stiffness values. In 3/1 twill woven fabric, floating portions of the warp yarns are interlaced with only one weft yarn. In the same way, floating weft yarns in back face are interlaced with only one warp yarn, hence $3 / 1$ twill woven fabric reinforced composite resisted least against forces applied during impact loading and the specimen $C$ deformed easily. The specimen $C$ has the lowest peak force and impact bending stiffness values. In addition to this, $3 / 1$ Twill weave has high weave interlacing coefficient, that is to say it has high crimp, therefore specimen $C$ reinforced with $3 / 1$ twill woven fabric have the highest deflection. 3/3 twill weave has the lowest weft yarn interlacing, namely it has lowest weft yarn crimp, thus specimen $F$ reinforced with $3 / 3$ twill woven fabric have the lowest deflection.

Consequently, 3/1 twill woven fabric reinforced composite can be proposed to be used in industrial applications, which are subjected to tensile forces in lengthways and width wise directions, respectively. On the other hand, the usage of $2 / 2$ broken twill fabric reinforced composite in weft direction can be suggested for applications, which require elasticity. Additionally, $3 / 3$ twill woven fabric reinforced composite can be proposed to be used as technical textiles, which are subjected to impact forces. Future research should be conducted on the physical properties of multiple layered twill derivative woven fabric reinforced composites and industrial applications including civil engineering, automotive, marine, aviation.

\section{REFERENCES}

1. Başer G., 2004, "Technique and Art of Weaving”, Vol: 1, Punto Publishing, İzmir (in Turkish).

2. Adumitroaie A. and Barbero E.J., 2012, "Stiffness and Strength Prediction for Plain Weave Textile Reinforced Composites", Mechanics of Advanced Materials and Structures, Vol: 19(1-3), pp: 169-183.

3. Chen, G. and Ding X., 2006, "Breaking Progress Simulation and Strength Prediction of Woven Fabric under Uni-Axial Tensile Loading", Textile Research Journal, Vol: 76(12), pp: 875-882.

4. Dabiryan H., Jeddi A.A.A. and Rastgo A., 2010, "The Influence of Frictional Energy on the Load-Extension Behavior of Plain Woven Fabrics", Textile Research Journal, Vol: 80(20), pp: 2223-2229.

5. Bilisik K., Karaduman N. and Bilisik N.E., 2016, "Chapter 3: Fibre Architectures for Composite Applications", Book Title: Fibrous and Textile Materials for Composite Applications, Ed: Raul Fangueiro and Sohel Rana, Springer Science+Business Media, Singapore, pp: 75-134.

6. Adanur S. and Onal L., 2001, "Factors Affecting the Mechanical Properties of Laminated Glass/Graphite-Epoxy Hybrid Composites", Journal of Industrial Textiles, Vol: 31(2), pp: 123-133.

7. Pothan L.A., Mai Y., Thomas S. and Li R., 2008, "Tensile and Flexural Behavior of Sisal Fabric/Polyester Textile Composites Prepared by Resin Transfer Molding Technique", Journal of Reinforced Plastics and Composites, Vol: 27(16-17), pp: 1847-1866.

8. Shonaike G.O., Lang Y. and Odusanya S., 2000, "A Preliminary Investigation of Tensile Properties of Glass-Mat Woven-Fabric-Reinforced Thermoplastic Elastomer Composites", Journal of Thermoplastic Composite Materials, Vol: 13(2), pp: 102-118.

9. Chen X., Spola M., Paya J.G. and Sellabona P.M., 1999, "Experimental Studies on the Structure and Mechanical Properties of Multi-Layer and AngleInterlock Woven Structures", Journal of the Textile Institute, Vol: 90(1), pp: 91-99.

10. Perumalraj R., Dasaradhan B. and Nalankilli G., 2010, "Copper, Stainless Steel, Glass Core Yarn, and Ply Yarn Woven Fabric Composite Materials Properties", Journal of Reinforced Plastics and Composites, Vol: 29(20), pp: 3074-3082.

11. Karahan M., 2011, "Investigation of Damage Initiation and Propagation in $2 \times 2$ Twill Woven Carbon/Epoxy Multi-Layer Composites", Textile Research Journal, Vol: 81(4), pp: 412-428.

12. Abot J.L., Gabbai R.D. and Harsley K., 2011, "Effect of Woven Fabric Architecture on Interlaminar Mechanical Response of Composite Materials: An Experimental Study", Journal of Reinforced Plastics and Composites, Vol: 30(24), pp: 2003-2014.

13. Arju S.N., Afsar A., Khan M.A. and Das D.K., 2015, "Effects of Jute Fabric Structures on the Performance of Jute-Reinforced Polypropylene Composites", Journal of Reinforced Plastics and Composites, Vol: 34(16), pp: 1306-1314.

14. Bilisik K., 2014, "Analysis and Stick-Slip Properties of Woven Fabric in Pull-Out Method", Industria Textila, Vol: 65(4), pp: 181-189.

15. Kadir B. and Gaye Y., 2014, "Warp and Weft Directional Tensile Properties of Multistitched Biaxial Woven E-Glass/Polyester Composites”, Journal of the Textile Institute, Vol: 105(10), pp: 1014-1028.

16. Kadir B. and Gaye Y., 2014, "Experimental Characterization of Multistitched Two Dimensional (2D) Woven E-Glass/Polyester Composites under Low Velocity Impact Load", Journal of Composite Materials, Vol: 48(17), pp: 2145-2162.

17. Özdemir H. and Içten B.M., 2017, "The Mechanical Performance of Plain and Plain Derivative Woven Fabrics Reinforced Composites: Tensile and Impact Properties", Journal of the Textile Institute, DOI: 10.1080/00405000.2017.1333719, pp: 1-13.

18. Aly N.M., Saad M.A., Sherazy E.H., Kobesy O.M. and Almetwally A.A., 2013, "Impact Properties of Woven Reinforced Sandwich Composite Panels for Automotive Applications", Journal of Industrial Textiles, Vol: 42(3), pp: 204-218.

19. Yan R. and Chen X., 2016, "Aramid/Epoxy Composites with Angle-Laid Reinforcement Constructions for Ballistic Protection", Journal of Industrial Textiles, Vol: 45(5), pp: 765-779. 
20. Padaki N.V., Alagirusamy R., Deopura B. and Fangueiro R., 2010, "Influence of Preform Interlacement on the Low Velocity Impact Behavior of Multilayer Textile Composites", Journal of Industrial Textiles, Vol: 40(2), pp: 171-185.

21. Hosur M., Adya M., Alexander J., Jeelani S., Vaidya U. and Mayer A., 2003, "Studies on Impact Damage Resistance of Affordable Stitched Woven Carbon/Epoxy Composite Laminates", Journal of Reinforced Plastics and Composites, Vol: 22(10), pp: 927-952.

22. Naik N. and Reddy K.S., 2002, "Delaminated Woven Fabric Composite Plates under Transverse Quasi-Static Loading: Experimental Studies", Journal of Reinforced Plastics and Composites, Vol: 21(10), pp: 869-877.

23. Naik N., Borade S., Arya H., Sailendra M. and Prabhu S., 2002, "Experimental Studies on Impact Behaviour of Woven Fabric Composites: Effect of Impact Parameters", Journal of Reinforced Plastics and Composites, Vol: 21(15), pp: 1347-1362.

24. Naik N., Meduri S. and Chandrasekher Y., 2001, "Polymer Matrix Woven Fabric Composites Subjected to Low Velocity Impact: Part III—Effect of Incident Impact Velocity and Impactor Mass", Journal of Reinforced Plastics and Composites, Vol: 20(9), pp: 720-743.

25. Naik N.K., Sekher Y.C. and Meduri S., 2000, "Damage in Woven-Fabric Composites Subjected to Low-Velocity Impact", Composites Science and Technology, Vol: 60(5), pp: 731-744.

26. Atas C. and Sayman O., 2008, "An Overall View on Impact Response of Woven Fabric Composite Plates", Composite Structures, Vol: 82(3), pp: 336-345.

27. Mariatti M., Jannah M., Abu Bakar A. and Khalil H.A., 2008, "Properties of Banana and Pandanus Woven Fabric Reinforced Unsaturated Polyester Composites", Journal of Composite Materials, Vol: 42(9), pp: 931-941.

28. Sinnppoo K., Arnold L. and Padhye R., 2010, "Application of Wool in High-Velocity Ballistic Protective Fabrics", Textile Research Journal, Vol: 80(11), pp: 1083-1092.

29. Marsyahyo E., Jamasri, Rochardjo H.S.B. and Soekrisno, 2009, "Preliminary Investigation on Bulletproof Panels Made from Ramie Fiber Reinforced Composites for NIJ Level II, IIA, and IV", Journal of Industrial Textiles, Vol: 39(1), pp: 13-26.

30. Pothan L.A., Potschke P., Habler R. and Thomas S., 2005, "The Static and Dynamic Mechanical Properties of Banana and Glass Fiber Woven FabricReinforced Polyester Composite", Journal of Composite Materials, Vol: 39(11), pp: 1007-1025.

31. Ashenhurst T.R., 1884, "A Treatise on Textile Calculations and the Structure of Fabrics", Broadbent, Huddersfield, Yorkshire.

32. Galceran V., 1962, "Weaving Technology", Technical University of Catalonia, Terrassa (in Spanish).

33. Goren A. and Atas C., 2008, "Manufacturing of Polymer Matrix Composites Using Vacuum Assisted Resin Infusion Molding", Archives of Materials Science and Engineering, Vol: 34(2). pp: 117-120.

34. ASTM D3039/D3039M - 14, 2016, "Standard Test Method for Tensile Properties of Polymer Matrix Composite Materials"

35. İkiz F., Püskülcü H. and Eren Ş., 1998, “Introduction to Statistics”, Barış Publishing, İzmir (in Turkish).

36. Icten B.M., Atas C., Aktas M. and Karakuzu R., 2009, "Low Temperature Effect on Impact Response of Quasi-Isotropic Glass/Epoxy Laminated Plates", Composite Structures, Vol: 91(3), pp: 318-323.

37. Atas C. and Liu D., 2008, "Impact Response of Woven Composites with Small Weaving Angles", International Journal of Impact Engineering, Vol: 35(2), pp: $80-97$.

38. Içten B.M. and Karakuzu R., 2008, "Effects of Weaving Density and Curing Pressure on Impact Behavior of Woven Composite Plates", Journal of Reinforced Plastics and Composites, Vol: 27(10), pp: 1083-1092.

39. Liu D., 2004, "Characterization of Impact Properties and Damage Process of Glass/Epoxy Composite Laminates", Journal of Composite Materials, Vol: 38(16), pp: 1425-1442.

40. Liu D., 1988, "Impact-Induced Delamination—A View of Bending Stiffness Mismatching", Journal of Composite Materials, Vol: $22(7)$, pp: 674-692. 